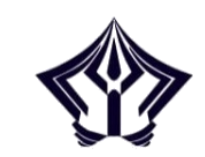

ANFUSINA: JOURNAL OF PSYCHOLOGY

http://ejournal.radenintan.ac.id/index.php/anfusina

DOI: //dx.doi.org/10.24042/ajp.v2i2.6099

Volume 2, Nomor 2, Oktober Tahun 2019

\title{
Hubungan Antara Successfull Aging Dan Penyesuaian Diri Lanjut Usia Dengan Penerimaan Diri
}

\author{
Khoiriya Ulfah \\ Program Studi Psikologi Islam \\ Universitas Islam Negeri Raden Intan Lampung \\ khoiriyahulfah@radenintan.ac.id \\ Annisa Fatin Nur Azizah Thoha \\ Program Studi Psikologi Islam \\ Universitas Islam Negeri Raden Intan Lampung \\ annisafatinnur@gmail.com \\ Abdul Qohar \\ Program Studi Psikologi Islam \\ Universitas Islam Negeri Raden Intan Lampung \\ abdul.qohar@radenintan.ac.id
}

\begin{abstract}
This research begins with the thought that successful aging and adjustment have a relationship with self-acceptance in elderly individuals. The purpose of this study was to determine the relationship between successfull aging and self-adjustment with the self-acceptance of retired member organizations (PWRI) of Lampung Province. The hypothesis proposed in this study is that there is a relationship between successfull aging and old age adjustment and self-acceptance. The population in this study were members of the Republic of Indonesia Wredatama Association (PWRI) Lampung Ranting I Kedaton, Bandar Lampung city. The sampling method for this research is to use population techniques
\end{abstract}


that refer to Suharsimi Arikunto's theory, that if the subject is less than 100 people, it is better to take all so that the research is a population study. The sample taken in this study were all PWRI members who held monthly meetings at the PWRI meeting hall on Landak street No. 1 Kedaton, Bandar Lampung city. The sample in this study was obtained as many as 60 members of the Republic of Indonesia Wredatama Pensioners (PWRI). The data collection method uses three scales namely self-acceptance scale, successfull aging scale and adjustment scale with likert scale model. Data collected were analyzed by two predictor regression tests with the help of SPSS 16.0 for windows. Based on the results of the data analysis above, it means that the proposed hypothesis can be accepted and it can be concluded that there is a relationship between successfull aging and adjustment of old age with selfacceptance in retirees.

\begin{abstract}
Abstrak
Penelitian ini berawal dari pemikiran bahwa successfull aging dan penyesuaian diri memiliki hubungan dengan penerimaan diri pada individu lanjut usia. Tujuan penelitian ini adalah untuk mengetahui hubungan antara successfull aging dan penyesuaian diri dengan penerimaan diri para pensiunan anggota organisasi (PWRI) Persatuan Wredatama Republik Indonesia Provinsi Lampung. Hipotesis yang diajukan dalam penelitian ini adalah ada hubungan antara successfull aging dan penyesuaian diri lanjut usia dengan penerimaan diri. Populasi dalam penelitian ini adalah anggota (PWRI) Persatuan Wredatama Republik Indonesia provinsi lampung Ranting I Kedaton, kota Bandar Lampung. Metode pengambilan sampel untuk penelitian ini adalah dengan menggunakan teknik populasi yang mengacu pada teori Arikunto, bahwa apabila subjek kurang dari 100 orang maka lebih baik di ambil semua sehingga penelitiannya merupakan penelitian populasi. Sampel yang di ambil dalam penelitian ini adalah seluruh anggota PWRI yang melakukan pertemuan bulanan di gedung pertemuan PWRI. Sampel dalam penelitian ini diperoleh sebanyak 60 orang anggota pensiunan (PWRI) Persatuan Wredatama Republik Indonesia. Metode pengumpulan data menggunakan tiga skala yaitu, skala penerimaan diri, skala successfull aging dan skala penyesuaian diri dengan model skala likert. Data yang terkumpul di analisis dengan uji regresi dua prediktor dengan bantuan program SPSS 16.0 for windows. Hasil analisis data menunjukkan bahwa ada hubungan antara successfull aging dan penyesuaian diri usia lanjut dengan penerimaan diri pada pensiunan.
\end{abstract}

Keywords = Self Acceptance, Self Adjustment, Successful Aging. 


\section{Pendahuluan}

Setiap individu akan mengalami fase dimana dirinya akan menjadi tua dan kehilangan pekerjaan seperti pensiun. Masa individu memulai bekerja dinamakan "saat bekerja" dan setelah mengabdikan dirinya pada dinas atau perusahaan selama berpuluh-puluh tahun tiba pada masa akhirnya disebut "pensiun" Hasibuan (dalam Adhiwardani, 2002).

Bagi para pekerja terutama para pegawai negeri diperlukan adanya kesiapan diri untuk menjalani kehidupan pensiun baik secara psikologis maupun secara finansial. Matthews (1993) menyatakan bahwa penerimaan diri merupakan suatu keadaan dimana individu memiliki keyakinan akan karakteristik dirinya, serta mampu dan mau untuk hidup dengan keadaan tersebut. Individu dengan penerimaan diri akan mampu menghadapi kenyataan dirinya yang dimiliki serta mengetahui kelemahan dan kelebihan akan dirinya.

Diperlukan adanya penerimaan diri yang positif bagi para pensiunan untuk melewati fase pensiun. Hal itu dikarenakan self acceptance (penerimaan diri) merupakan salah satu fungsi psikologis yang berpengaruh terhadap psychological well being pada tercapainya successfull aging. Senada dengan penelitian yang dilakukan Hardy dan Heyes (dalam Adhiwardani, 2002) bahwa individu yang menerima masa pensiun dapat merasa bahagia dan gembira karena memiliki waktu luang untuk mengerjakan segala sesuatu. Namun sebaliknya ada individu yang tidak dapat menerima keadaan pensiun dengan merasa cemas dan merasa takut tidak dapat bersosialisasi lagi di lingkungannya. Perasaan bahagia secara psikologis (Psychological well being) yang timbul karena penerimaan diri pada keadaan pensiun ini merupakan salah satu aspek dalam successfull aging yang baik.

Permasalahan yang seringkali terjadi pada para lansia di usia lanjut apabila mereka berada pada kondisi despair sesuai dengan teori perkembangan psikososial Erikson, individu lanjut usia memiliki tugas perkembangan terakhir yaitu integrity vs despair. Individu lanjut usia yang dapat merefleksikan masa lalunya dan dapat meninjau kehidupannya serta menemukan arti dan integrasi maka akan mencapai integritas. Bagi Erikson, pencapaian tertinggi pada masa lanjut usia adalah adanya rasa ego integrity atau integritas diri, sebuah pencapaian yang didasari refleksi mengenai jalan hidup seseorang.

Tahapan kedelapan dan terakhir dari rentang hidup, yaitu integritas diri dan keputusasaan (ego integrity versus despair), seorang lanjut usia perlu mengevaluasi dan menerima kehidupan 
mereka, daripada menyerah terhadap keputusasaan karena ketidakmampuan untuk melakukan hal yang berbeda pada masa lalu (Erikson, Erikson, \& Kivnick, 1986). Para lansia yang sukses dalam tugas terakhir ini akan memperoleh perasaan kebermaknaan hidup mereka dalam tataran sosial yang lebih tinggi dengan menerima kehidupan yang telah dijalani tanpa ada rasa penyesalan, menerima ketidaksempurnaan pada diri, serta keadaan saat pensiun.

Kondisi lanjut usia yang mengalami despair tergambarkan dalam beberapa penelitian. Sebuah penelitian yang dilakukan oleh Permatasari (2010) pada para lansia penderita diabetes mellitus di RSUD Dr. Sardjito Yogyakarta, yang mengalami ketegangan psikologis diakibatkan pengaturan pola hidup dan pengobatan penyakit tersebut yang memerlukan jangka waktu panjang. Berkaitan dengan ketegangan psikologis tersebut maka dapat dilakukan sebuah mekanisme penerimaan diri oleh para pasien dengan menerima kenyataan yang ada dengan penyakitnya tersebut. Rubin (1974) menyatakan bahwa penerimaan diri merupakan sikap yang mencerminkan perasaan senang sehubungan dengan kenyataan yang ada pada diri sendiri.

Berapapun usia seorang pensiunan, mungkin bukan suatu hal penting yang perlu diperbincangkan. Namun justru efek dari usia dan keadaan tersebutlah yang memiliki peranan penting dalam kehidupan seorang pensiunan, hal tersebut berdasarkan wawancara yang dilakukan dengan beberapa pensiunan anggota PWRI (Persatuan Wredatama Republik Indonesia) di daerah Seputih Mataram Lampung Tengah. Hal yang seringkali menjadi permasalahan dan menghambat aktivitas mereka ialah kondisi kesehatan mereka seperti mudah lelah, pegal-pegal, sakit ketika berjalan kaki, mudah jatuh, asam urat dan lain sebagainya.

Berdasarkan wawancara dilakukan pada tanggal 27 juni 2018, hasil dari wawancara tersebut bahwasannya para pensiunan tersebut merasa bahagia setelah dinyatakan pensiun karena telah lepas dari tanggung jawab serta pekerjaan mereka sebelumnya. Seperti yang diungkapkan oleh Hasibuan (dalam Adhiwardani, 2002), idealnya masa pensiun dirasakan oleh individu sebagai suatu kebahagiaan, suatu masa yang ditunggu-tunggu karena dirinya merasa sudah cukup bekerja, merasa puas dan sudah merasa saatnya mereka tinggalkan.

Hadjam (dalam Adhiwardani, 2002) menjelaskan bahwa perubahan peran, perubahan keinginan dan nilai, perubahan secara keseluruhan terhadap pola individu mengalami masa pensiun 
(Hurlock 1999, dalam Adhiwardani, 2002) dapat menimbulkan perbedaan sikap penerimaan atau penolakan.

Di sisi lain, individu lanjut usia pasti memiliki harapan untuk menghabiskan sisa-sisa waktunya dengan baik serta penuh keberhasilan dan kesuksesan, baik secara biologis, psikologis, dan sosial. Lanjut usia yang berhasil (successfull aging) didefinisikan oleh Rowe dan Kahn (1997) harus mampu menanggulangi penyakit dan ketidakmampuan fisik, memiliki kapasitas yang tinggi dari fungsi kognitif dan fisik, serta memiliki keterikatan yang aktif dengan kehidupan di sekitarnya.

Hal tersebut seperti yang dilakukan oleh para pensiunan di daerah Seputih Mataram Lampung Tengah, para pensiunan banyak menjalani kegiatan dan aktivitas baik dirumah dan juga di lingkungan sosial seperti bercocok tanam aneka sayuran dan bunga, memelihara ikan konsumsi di kolam. Lain hal dengan para pensiunan yang berdomisili di Kedaton kota Bandar Lampung, mengikuti berbagai kegiatan di organisasi PWRI (Persatuan Wredatama Republik Indonesia) dan juga senam lansia.

Suardiman (2011) merumuskan salah satu strategi untuk mencapai keberhasilan bagi para lanjut usia adalah dengan menggunakan waktu sebanyak mungkin dan sebaik-baiknya untuk melakukan hal yang bermakna. Kegiatan yang dilakukan sekedar untuk mengisi waktu luang cenderung mengurangi rasa tidak bahagia pada lanjut usia. (Greenfield \& Marks, 2004).

Dikarenakan banyaknya aktivitas, para lanjut usia yang menjalani masa pensiun dapat mengalihkan perhatian dan fokusnya dari kondisi diri sendiri kepada hal lain yang bermanfaat baik itu untuk penanggulangan kondisi pribadinya maupun bagi lingkungan sekitar. Berdasarkan wawancara yang dilakukan dengan Ketua Organisasi Persatuan Wredatama Republik Indonesia (PWRI) provinsi Lampung, Bapak H. Lukman Hakim S.H, MM beliau mengatakan bahwa dengan berkumpul dengan sesama pensiunan dalam organisasi akan meningkatkan energi positif serta meningkatkan kebahagiaan.

Masa pensiun adalah masa yang datangnya berdasarkan pencapaian usia tertentu. Banyak orang beranggapan bahwa masa pensiun merupakan tanda bahwa seseorang sudah mengalami penuaan dan tidak dapat bekerja secara produktif lagi, pensiun adalah masa transisi signifikan yang mempengaruhi perubahan. (Seligman, 1980) menjelaskan bahwa ketika hal ini terjadi, perubahan fisiologis 
tidak dapat dihindari dan juga dapat mengakibatkan perubahan emosional.

Permasalahan selanjutnya yaitu berkenaan dengan penyesuaian diri dalam menjalani masa pensiun berkaitan dengan penelitian. Berdasarkan wawancara yang dilakukan dengan beberapa pensiunan di daerah Seputih Mataram Lampung Tengah. Wawancara dilakukan pada tanggal 27 juni 2018, hasil dari wawancara tersebut bahwasannya para pensiunan tersebut seringkali merasa ketinggalan zaman, merasa tidak lagi terpakai dan merasa tersisihkan terutama dengan kalangan yang lebih muda. Hal tersebut seperti yang diungkapkan oleh Hurlock (2003) dalam proses ini mereka tidak hanya menyesuaikan diri dengan kondisi pekerjaan saja tetapi mereka juga harus menyadari bahwa peran dirinya dalam lingkungan semakin berkurang sesuai dengan semakin bertambahnya usia. Akibatnya, statusnya dalam kelompok sosial semakin berkurang dan mereka juga mengalami kesulitan dalam menyesuaikan diri terhadap masa pensiun.

\section{Metode Penelitian}

Penelitian ini merupakan jenis penelitian kuantitatif. Subjek penelitian berjumlah sebanyak 60 orang anggota pensiunan (PWRI) Persatuan Wredatama Republik Indonesia Kedaton kota Bandar Lampung dan merupakan lansia yang sudah pensiun dari berbagai instansi pemerintah di Provinsi Lampung. Pengumpulan data dalam penelitian ini dilakukan dengan menyebarkan tiga buah skala, yaitu:

\section{Skala Penerimaan Diri}

Untuk mengungkap penerimaan diri ini digunakan skala berdasarkan teori Ryff (1989), yaitu: (1) bersikap positif dengan orang lain, (2) bersikap positif dengan masa lalu, dan (3) bersikap positif dalam berhubungan dengan orang lain.

\section{Skala Penyesuaian Diri}

Untuk mengungkap Penyesuaian Diri ini digunakan skala berdasarkan teori (Schneider,1964), yaitu (1) kontrol terhadap emosi; (2) mekanisme pertahanan diri; (3) frustasi personal yang minimal; (4) pertimbangan rasional dan kemampuan mengarahkan diri; (5) kemampuan untuk belajar dan 
memanfaatkan pengalaman masa lalu; dan (6) sikap realistis dan objektif.

\section{Skala Successfull Aging}

Untuk mengungkap successfull aging ini digunakan skala berdasarkan teori Reker, yaitu: (1) functional well; (2) SOC (selection, optimization, compensation), (3) primary and secondary control (4) psychological well being.

Data yang diperoleh dalam penelitian ini akan dianalisis dengan teknik analisis regresi berganda atau analisis regresi dua prediktor adalah suatu teknik statistik parametrik yang digunakan untuk menguji pertautan dua prediktor $\left(\mathrm{X}_{1}\right.$ dan $\left.\mathrm{X}_{2}\right)$ dengan variabel tergantung (Y) (Tulus, 2015). Pada penelitian ini $\mathrm{X}_{1}$ yaitu variabel penyesuaian diri dan $\mathrm{X}_{2}$ successfull aging dan variabel tergantung (Y) yaitu penerimaan diri.

\section{Hasil dan Pembahasan}

Penelitian ini menggunakan try out terpakai dikarenakan jumlah subjek dan kondisi dari dari subjek yang merupakan para lanjut usia, tidak memungkinkan akan diberikan skala sebanyak dua kali. Pada proses penelitian ini sampel yang diperoleh adalah 60 orang anggota PWRI yang sedang melaksanakan pertemuan bulanan.

Skala yang digunakan pada penelitian ini adalah skala penerimaan diri, skala successfull aging dan skala penyesuaian diri. Skala penerimaan diri terdiri dari 60 aitem dimodifikasi dari penelitian (Nurlia Muslimah, 2010), skala successfull aging 48 aitem adalah skala yang dimodifikasi dari penelitian (Agus, 2013) dan skala penyesuaian diri terdiri dari 60 aitem adalah skala yang disusun oleh peneliti.

Peneliti melakukan analisis data dengan analisis regresi berganda. Perhitungan data dilakukan dengan menggunakan program SPSS 16.0 For Windows. Setelah dilakukan analisis, adapun hasilnya yaitu:

1. Rx1.2-y =0,679 dengan $\mathrm{p}=0,000$ yang berarti ada hubungan antara successfull aging dan penyesuaian diri lanjut usia dengan penerimaan diri pada pensiunan. 
2. rxIy $=0,646$ dengan $p=0,000$ yang berarti ada hubungan yang signifikan antara successfull aging dan penerimaan diri.

3. $\mathrm{rx} 2 \mathrm{y}=0,634$ dengan $\mathrm{p}=0,000$ yang berarti ada hubungan yang signifikan antara penyesuaian diri dan penerimaan diri.

Berdasarkan penelitian yang telah dilakukan diketahui hasilnya bahwa ada hubungan antara successfull aging dan penyesuaian diri lanjut usia dengan penerimaan diri pada masa pensiun. Hal ini dapat ditunjukkan dengan hasil nilai koefisien korelasi $(\mathrm{R})=0.679$ dan $\mathrm{F}$ hitung $=22.690$ dengan $\mathrm{p}=0.000$ hal ini berarti bahwa variabel successfull aging dan penyesuaian diri dapat dijadikan variabel bebas (prediktor) untuk memprediksi ataupun mengukur penerimaan diri. Karena salah satu komponen kebahagiaan dan kesuksesan bagi invidu lanjut usia adalah penerimaan diri (Sartini, 2002).

Pada penelitian ini juga menghasilkan data yang membuktikan bahwa ada hubungan yang signifikan antara successfull aging dan penerimaan diri, hasil ini ditunjukkan dengan nilai rxIy $=0.646$ dengan $p=0.000$. Adanya hubungan diantara kedua variabel ini, yaitu successfull aging dan penerimaan diri menunjukkan bahwa semakin tinggi successfull aging maka penerimaan diri akan semakin tinggi. Sumbangan efektif dari successfull aging usia lanjut pada pensiunan adalah (Beta $x$ ZeroOrder: $0.469 \times 0.710=0.3329 \times 100=33.29 \%$

Successfull aging bisa di artikan sebagai kondisi fungsional lansia berada pada kondisi maksimum atau optimal, sehingga memungkinkan mereka bisa menikmati masa tuanya dengan penuh makna, membahagiakan, berguna dan berkualitas. Successfull aging pada pensiunan yang telah dijelaskan diatas memberikan mampu memberikan kontribusi yang besar pada penerimaan diri para pensiunan anggota PWRI. Seperti yang di ungkapkan Hurlock (2004) ada beberapa faktor yang menyebabkan seorang lansia berada pada kondisi maksimum atau optimal di masa tuanya, yakni: Kemampuan menyesuaikan diri dan menerima segala perubahan dan kemunduran yang di alami.

Penerimaan diri merupakan suatu tingkatan kesadaran individu tentang karakteristik pribadinya dan adanya kemauan untuk hidup dengan keadaan tersebut (Pannes (dalam Hurlock, 1973)). Individu dengan penerimaan diri merasa bahwa 
karakteristik tertentu yang dimiliki adalah bagian diri yang tidak terpisahkan, yang selanjutnya dihayati sebagai anugerah. Segala apa yang ada pada dirinya dirasakan sebagai sesuatu yang menyenangkan, sehingga individu tersebut memiliki keinginan untuk terus dapat menikmati kehidupan sehingga menyebabkan seorang lanjut usia khususnya para pensiunan berada pada kondisi maksimum atau optimal.

Selain dari successfull aging, ada penyesuaian diri yang mempunyai kontribusi dalam meningkatkan nilai penerimaan diri usia lanjut pada pensiunan. Penyesuaian diri merupakan suatu proses dinamika yang bertujuan untuk merubah perilaku dalam membentuk hubungan yang lebih sesuai atau menyenangkan antara dirinya dengan lingkungan (Fahmy, 2004). Apabila individu lanjut usia mampu mengisi masa pensiunnya dan dapat menyesuaikan diri dengan baik, maka akan berdampak positif terhadap kelangsungan kehidupan masa pensiun. Berdasarkan hasil penelitian juga membuktikan ada hubungan antara penyesuaian diri dengan penerimaan diri, yang terlihat dari nilai $\mathrm{rx} 2 \mathrm{y}=0.634$ dengan $\mathrm{p}=0.000$. Adanya hubungan antara penyesuaian diri dengan penerimaan diri pada pensiunan menunjukkan bahwa semakin tinggi penyesuaian diri maka semakin tinggi penerimaan diri. Sumbangan efektif atau peranan yang diberikan dari konsep diri adalah (Beta $\times$ Zero-Order: $0.292 \times 0.680=0.1985 \times 100=$ $19.85 \%)$.

Penyesuaian diri ini seringkali dimengerti sebagai kemampuan individu untuk menyamakan diri dengan harapan kelompok, sebagai mengatur kembali ritme hidup atau jadwal harian, dan sebagai suatu pembelajaran hidup dengan sesuatu yang tidak dapat diubah (Siswanto, 2007). Menurut Siswanto (2007), istilah penyesuaian diri dalam bahasa inggris memiliki dua kata yang berbeda maknanya, yaitu adaptasi (adaptation) dan penyesuaian (adjusment). Kedua istilah tersebut sama-sama mengacu pada pengertian mengenai penyesuaian diri, tetapi memiliki perbedaan yang mendasar.

Adaptasi memiliki pengertian individu melakukan penyesuaian diri dengan lingkungan yang menekankan pada perubahan yang individu lakukan terhadap dirinya agar tetap bisa sesuai dengan lingkungannya. Penyesuaian dipahami sebagai mengubah lingkungan agar menjadi lebih sesuai dengan diri 
individu, pengertian ini menekankan pada perubahan lingkungan yang dilakukan oleh individu sehingga tetap sesuai dengan dirinya. Penyesuaian yang dimaksud dalam penelitian ini meliputi penyesuaian diri lanjut usia baik dalam pengertian adaptation maupun adjusment.

Seperti menurut Havighurst dan Duvall (dalam Hardywinoto, 1991) menguraikan beberapa tugas perkembangan (developmental tasks) di antaranya ialah penyesuaian terhadap penurunan fisik dan psikis, penyesuaian terhadap masa pensiun dan penurunan pendapatan dan menerima dirinya sebagai seorang lanjut usia. Hal tersebut sangat berkaitan dengan hasil penelitian yang menunjukkan bahwa adanya hubungan yang signifikan antara penyesuaian diri dengan penerimaan diri usia lanjut pada para pensiunan dan dapat disimpulkan bahwasannya para pensiunan tersebut telah melaksanakan tugas perkembangannya dengan baik.

Terwujudnya successfull aging yang tinggi juga dipengaruhi oleh oleh salah satu fungsi psikologis yang positif yaitu self acceptance (penerimaan diri), individu yang mempunyai tingkat penerimaan diri yang baik ditandai dengan bersikap positif terhadap diri sendiri, mengetahui serta menerima aspek-aspek yang terdapat dalam dirinya, baik positif maupun negatif dan memiliki pandangan yang positif terhadap masa lalu. Seperti yang di ungkapkan oleh Berk (dalam Suadirman, 2011 : 181) mendeskripsikan faktor-faktor yang mempengaruhi pencapaian successfull aging yakni menerima perubahan yang membantu perkembangan kepuasan hidup.

Pada penelitian yang dilakukan oleh Khusniyah, Ervina, Istiqomah yang berjudul "Studi Tentang Successful Aging pada lansia di UPT Pelayanan Sosial lanjut usia Kecamatan Glenmore Kabupaten Banyuwangi. Penelitian tersebut bertujuan untuk memahami proses pembentukan successful aging dan faktor-faktor yang mempengaruhi terbentuknya successful aging, penelitian tersebut mengungkapkan bahwa terdapat beberapa proses pembentukan successful aging pada lansia selama berada di UPT, salah satunya yaitu penerimaan diri.

Berdasarkan hasil analisis ketiga variabel dan diketahui jumlah sumbangan efektif masing-masing variabel bebas terhadap variabel tergantung yaitu variabel successfull aging pada para pensiunan memberikan sumbangan efektif sebesar $33.29 \%$ dan 
penyesuaian diri memberikan sumbangan efektif sebesar $19.85 \%$ yang berarti ada $53.14 \%$ kontribusi yang diberikan kedua variabel tersebut kepada variabel penerimaan diri. Selebihnya, ada $46.86 \%$ disebabkan oleh faktor-faktor lain tersebut misalnya yaitu: usia, latar belakang pendidikan, dan dukungan sosial. Seperti yang di ungkapkan oleh Kurniawan (2013) dimana kemampuan penerimaan diri yang dimiliki seseorang berbeda-beda tingkatannya sebab kemampuan tersebut dipengaruhi oleh beberapa faktor, antara lain usia, latar belakang pendidikan dukungan sosial serta dukungan emosional.

Bahwa ada hubungan yang signifikan antara dukungan sosial keluarga dan penerimaan diri bagi individu lanjut usia, dimana dukungan sosial yang diberikan oleh keluarga dapat berupa dukungan emosional, dukungan penghargaan, dukungan instrumental, dan dukungan informasi. Setiap dukungan memberikan pengaruh atau manfaat bagi individu yang menerimanya. Dukungan emosional berkaitan dengan salah satu faktor yang mempengaruhi penerimaan diri yaitu dengan tidak adanya gangguan emosional di dalam lingkungan dan dukungan emosional yang diberikan keluarga membuat individu dapat lebih baik dan lebih bahagia.

Untuk penelitian selanjutnya mampu mengembangkan kembali penelitian mengenai penerimaan diri usia lanjut pada pensiunan dengan faktor-faktor lain yang mempengaruhi penerimaan diri sesuai dengan faktor yang disebutkan pada paragraf di atas.

\section{Simpulan dan Saran}

Berdasarkan hasil analisis yang telah dilakukan dan pembahasan yang telah diuraikan diatas, maka dapat di ambil kesimpulan dari penelitian ini, yaitu:

1. Ada hubungan antara successfull aging dan penyesuaian diri lanjut usia dengan penerimaan diri dengan nilai koefisien korelasi $(\mathrm{R})=0.679$ dan $\mathrm{F}$ hitung $=22.690$ dengan $\mathrm{p}=0.000$ yang berarti bahwakedua variabel bebas dapat dijadikan sebagai variabel bebas untuk memprediksi penerimaan diri pada pensiunan. Kedua variabel bebas memberikan sumbangan efektif $53.14 \%$ secara keseluruhan. 
2. Ada hubungan yang signifikan antara successfull aging dan penerimaan diri dengan hasil diperoleh nilai rxIy $=0.646$ dengan $\mathrm{p}=0.000$ yang berarti. Hasil tersebut menunjukkan bahwa semakin tinggi successfull aging, maka semakin tinggi penerimaan diri dalam menjalankan masa pensiun. Sumbangan efektif dari successfull aging adalah $33.29 \%$.

3. Ada hubungan yang signifikan antara penyesuaian diri dan penerimaan diri dengan hasil diperoleh nilai $\mathrm{rx} 2 \mathrm{y}=0.634$ dengan $\mathrm{p}=0.000$ yang berarti. Hasil tersebut menunjukkan bahwa semakin tinggi penyesuaian diri maka semakin tinggi penerimaan diri pada pensiunan dalam menjalankan masa pensiun. Sumbangan efektif atau peranan yang diberikan dari penyesuaian diri adalah $19.85 \%$.

Berdasarkan hasil penelitian yang telah dilaksanakan dan kesimpulan yang telah dipaparkan diatas, maka penulis memberikan sumbangan saran kepada pihak-pihak terkait untuk dipertahankan.

\section{Bagi PWRI}

Peneliti menyarankan bagi organisasi PWRI diharapkan untuk tetap aktif dalam membina para lanjut usia yang menjadi anggotanya, selain itu juga lebih banyak dalam meningkatkan adanya kegiatan bagi para anggotanya terutama kegiatan dalam bidang keagamaan atau kerohanian, kesehatan dan kegiatan penyuluhan mengenai strategi dalam menghadapi masa pensiun serta pelatihan yang diadakan secara rutin. Agar para anggota PWRI dapat meningkatkan penyesuaian dirinya selama pensiun dan menerima berbagai perubahan yang terjadi dengan lapang dada dan penuh rasa syukur terhadap datangnya masa pensiun, dengan tetap aktif mengikuti berbagai kegiatan sosial agar tetap terjaga komunikasinya dengan lingkungan sekitar, lebih mendekatkan diri kepada Tuhan Yang Maha Esa menurut keyakinan masing-masing serta menyalurkan hobi yang dimiliki untuk mengisi waktu luang di masa pension.

2. Bagi Penelitian Selanjutnya

Untuk penelitian selanjutnya diharapkan agar dapat memperhatikan variabel yang mungkin berimplikasi dengan 
permasalahan tersebut misalnya faktor dukungan sosial keluarga.

\section{Referensi}

Azwar. (2007). Metode penelitian. Jakarta: Pustaka Pelajar.

Azizah, L. M. (2010). Keperawatan lanjut usia. Yogyakarta: Graha Ilmu.

Fisher, B. J. (1995). Successfull aging, life satisfaction, generativity in later life.

Chaplin, J. P. (2005). Kamus lengkap psikologi. Jakarta: Raja Grafindo Persada.

Agoes, D. (2007). Psikologi perkembangan anak usia tiga tahun pertama. Jakarta: PT Refika Aditama.

Desmita, R. (2008). Psikologi perkembangan. Bandung: PT. Remaja Rosdakarya.

Dorris. (2003). Succesfull and active aging, the journal on active aging.

Endah, S. (2002). Penerimaan diri pada lanjut usia ditinjau dari kematangan emosi. Yogyakarta: Universitas Gadjah Mada.

Hadi, S. (2015). Statistik. Yogyakarta: Pustaka Pelajar.

Hamidah, A. (2012). Studi eksplorasi successfull aging melalui dukungan sosial bagi lansia di indonesia dan malaysia. Surabaya: Fakultas Psikologi Universitas Airlangga.

Hardywinoto \& Setiabudhi, T. (1999). Panduan gerontologi menjaga keseimbangan kualitas hidup para lanjut usia. Jakarta: PT. Mekar Saudara Jaya.

Hawari, D. (2007). Sejahtera di usia senja dimensi psikoreligi pada lanjut usia (Lansia). Jakarta: FKUI, Gramedia Pustaka Utama.

Hurlock, B. (2004). Psikologi perkembangan. Jakarta: Erlangga.

Hurlock, E. B. (1993). Psikologi perkembangan (Edisi 1). Jakarta: Erlangga. 
Kaplan, H. I., \& Sadock, B. J. (1995). Comprehensive textbook of psychiatry. Philadelphia: Williams Wilkins.

Maulia, D. (2013). Penelitian tentang successfull aging (Studi tentang lanjut usia yang anak dan keluarganya tinggal bersama). Purwokerto: Universitas Muhammadiyah Purwokerto.

MO, U. (2013). Hubungan religiusitas dengan penerimaan diri padamasyarakat miskin. Jawa Barat: Universitas Gunadarma.

Nuhriawangsa, I., \& Sudiyanto, A. (2008). Psikiatri geriatri. Surakarta: Fakultas Kedokteran UNS.

Periantolo. (2015). Penyusunan skala psikologi asik, mudah \& bermanfaat. Yogyakarta: Pustaka Pelajar.

Santrock, J. W. (2003). Adolescence perkembangan remaja. Jakarta: Erlangga.

Sari, E. P. (2002). Penerimaan diri pada lanjut usia ditinjau dari kematangan emosi. Jurnal Psikologi, 2, 73-88.

Shihab, M. Q. (2002). Tafsir al-misbah pesan, kesan dan keserasian Al-Qur'an. Jakarta: Lentera Hati, 6, 481-483.

Sumanto. (2013). Psikologi perkembangan fungsi dan teori. Yogyakarta: Caps Publishing.

Syamsu, J. (2008). Teori kepribadian. Bandung: PT. Remaja Rosdakarya.

Tulus. (2015). Statistik dalam penelitian psikologi dan pendidikan. Malang: UMM Press.

Wafiqotul, Iin, \& Istiqomah. (2010). Studi tentang successfull aging pada lansia di UPT Pelayanan Sosial lanjut usia Kecamatan Glenmore Kabupaten Banyuwangi. Jember: Universitas Muhammadiyah Jember.

Yuki, S. (2010). Dinamika psikologis pencapaian successfull aging pada lansia yang mengikuti program yandu lansia. Purwokerto: Universitas Muhammadiyah Purwokerto. 